\title{
Deliberative multiattribute valuation of ecosystem services across a range of regional land-use, socioeconomic, and climate scenarios for the upper Merrimack River watershed, New Hampshire, USA
}

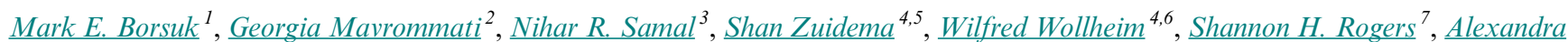 \\ M. Thorn ${ }^{8}$, David Lutz $^{9}$, Madeleine Mineau ${ }^{4}$, Curt Grimm ${ }^{10}$, Cameron P. Wake ${ }^{4,5}$, Richard Howarth ${ }^{9}$ and Kevin Gardner ${ }^{11}$
}

\begin{abstract}
We evaluate the relative desirability of alternative futures for the upper Merrimack River watershed in New Hampshire, USA based on the value of ecosystem services at the end of the 21 st century as gauged by its present-day inhabitants. This evaluation is accomplished by integrating land-use and socioeconomic scenarios, downscaled climate projections, biogeophysical simulation models, and the results of a citizen-stakeholder deliberative multicriteria evaluation. We find that although there are some trade-offs between alternative plausible futures, for the most part, it can be expected that future inhabitants of the watershed will be most satisfied if land-use planning in the intervening years prioritizes water supply and flood protection as well as maintenance of existing farmland and forest cover. With respect to climate change, it is expected that future watershed inhabitants will be more negatively affected by the projected loss of snow cover than the anticipated increase in hot summer days. More important than the specific results for the upper Merrimack River watershed, this integrative assessment demonstrates the complex yet ultimately informative potential to link stakeholder engagement with scenario generation, ecosystem models, and multiattribute evaluation for informing regional-scale planning and decision making.
\end{abstract}

Key Words: climate impacts; integrated assessment modeling; nonmonetary valuation; sustainability

\section{INTRODUCTION}

The 21 st century will undoubtedly bring myriad changes to the world's ecosystems and the many ways in which they support humankind. The convergence of a changing climate, growing population, and dynamic political environment leave open the possibility of many alternative futures (O'Neill et al. 2017). Local officials may feel that the major influence factors are operating at a scale that is too large to be managed. However, land use and natural resource decisions at the local and regional scale are critical mediators of the impacts of global and national trends on local ecosystems (Wardropper et al. 2016). It is also at the regional level that the value of many ecosystem services is determined (Malinga et al. 2013). This is not only because ecosystems often provide services that might otherwise be expected of states or municipalities (e.g., water treatment, flood protection, recreation and cultural settings, scenic amenities), but also because the demand for such services is often determined by regional history, beliefs, and norms (MacDonald et al. 2013, Cebrián-Piqueras et al. 2017).

For these reasons, efforts to value ecosystem services might be most effective when coupled with environmental modeling at a regional scale. In the United States, such a scale is likely to be larger than a single municipality but smaller than a state. This scale allows for consideration of changes in both local land cover and global climate while also linking terrestrial and aquatic biogeophysical processes at the level of the watershed (Costanza et al. 2002, García-Llorente et al. 2015). Local considerations regarding economic conditions, community history, cultural practices, and government service expectations can be respected while acknowledging constraints imposed by state regulations and resources (Castro et al. 2016a,b).

The importance of local sites, amenities, and activities to a community's residents and visitors are highly local and often intimately linked with a region's "sense of place" or "shared values" (Hausmann et al. 2016, Masterson et al. 2017). Irvine et al. (2016) describe shared values as representing the broader meaning and significance attributed to ecosystems beyond individual utility. They are derived from concerns regarding fairness, ethics, shared responsibility, and collective meaning and are often interrelated with stewardship obligations, sense of place, and the spiritual value of nature (Irvine et al. 2016). Chan et al. (2016) refer to these values as relational values and define them as the "preferences, principles, and virtues associated with relationships, both interpersonal and as articulated by policies and social norms." Irvine et al. (2016) assert that such values cannot be ascertained simply through an aggregation of individual utilities. Rather, these aspects of value are formed and shaped through social processes that require some form of community interaction.

In describing their deliberative value formation model, Kenter et al. (2016b) use social-psychological theory to articulate how shared, relational, or transcendental values may be formed in a group setting by asking participants to translate their principles into specific contextual values. The goal is for individuals to

${ }^{1}$ Civil and Environmental Engineering, Duke University, ${ }^{2}$ School for the Environment, University of Massachusetts Boston, ${ }^{3}$ Office of the Agency Chief Engineer, New York City Department of Environmental Protection, ${ }^{4}$ Earth Systems Research Center, University of New Hampshire, ${ }^{5}$ Department of Earth Sciences, University of New Hampshire, ${ }^{6}$ Department of Natural Resources and the Environment, University of New Hampshire, ${ }^{7}$ Community and Economic Development, Cooperative Extension, University of New Hampshire, ${ }^{8}$ Tufts University, ${ }^{9}$ Environmental Studies Program, Dartmouth College, ${ }^{10}$ Carsey School of Public Policy, University of New Hampshire, ${ }^{11}$ Civil and Environmental Engineering Department, University of New Hampshire 
distinguish their personal preferences from a broader narrative about what values ought to be shared. These shared values may be consistent with the self-interest of some individuals, but Irvine et al. (2016) assert that there remains a fundamental difference between the values that are held individually and those that are formed normatively in collaboration with others. Deliberative approaches to ecosystem service valuation have long been advocated (Costanza and Folke 1997, Costanza 2000), but few examples exist in the published literature.

Kenter et al. (2016b) proceed to identify the potential outcomes of a deliberative valuation process, including: changes in systemic understanding, changes in capacity to deliberate, triggering of dormant values, and shift in value orientation toward the common good. More practically, outputs of the process may include numerical characterizations of shared contextual values in the form of societal willingness-to-pay assessments or collective ratings or rankings. Like conventional economic approaches, the purpose of such a quantification is ultimately to understand better the relative value of one course of action over another. In this way, public sector decisions can be informed by values that capture the common good, rather than only the aggregated preferences of individuals (Wilson and Howarth 2002).

Kenter et al. (2016b) include as potential output of the deliberative valuation process a collective verdict or vote on specific courses of action or on how much society should be willing to pay for such actions. However, for the purposes of public sector decision making, there are strong arguments in favor of separating the task of predicting the specific consequences of any particular action from the task of putting a value on such consequences (Keeney 1992). Whether performed individually or collectively, the latter is clearly the role of citizen stakeholders, whereas the former is arguably a task for subject matter experts. Differentiating the two tasks helps to distinguish potential stakeholder disagreements over the expected consequences of alternative courses of action from disagreements over the relative importance of these consequences (Reichert et al. 2007).

The idea of separating expert assessment of consequences from stakeholder valuation of such consequences is supported by multiattribute value theory (MAVT). MAVT provides a framework for comparing alternative courses of action having outcomes over multiple dimensions that are measured in different units or cannot be quantified in monetary terms (Keeney and Raiffa 1976). This is done by identifying an attribute, or indicator, of each outcome dimension for which projections can be generated (typically using a model) corresponding to each possible course of action. The full range of each attribute across the various actions is then transformed to a measure of preference, and trade-off weights among the attributes are assessed that represent their relative preference importance. The value of each action is then gauged not by the total monetary value of that action's consequences but by the weighted sum of the nonmonetary preferences for each attribute.

When courses of action correspond to potential land use and climate changes and outcomes correspond to effects on ecosystems, then the attributes used in MAVT can be chosen to represent ecosystem services, and the relative preferences for those services should capture transcendental, or shared, values, in the sense of Kenter et al. (2016a). A variety of studies have used
MAVT to assess the nonmonetary value of ecosystem services to a region's stakeholders (e.g., Hostmann et al. 2003, Fontana et al. 2013, Karjalainen et al. 2013, Uhde et al. 2015), and a few have adopted a deliberative approach to multiattribute valuation (e.g., Proctor and Drechsler 2006, Oikonomou et al. 2011, Straton et al. 2011). There are very few examples for which stakeholders were explicitly asked to consider their transcendental values as part of the deliberative valuation process (e.g., Ranger et al. 2016).

We employed a deliberative method of multiattribute valuation of ecosystem services in the upper Merrimack River watershed (UMRW), New Hampshire, USA. Because we were interested in evaluating alternative climate and land-use scenarios for the year 2100, we motivated participants to consider themselves as "trustees" for future generations and to focus on shared societal values rather than on their own self-interest. This motivation was reinforced by structuring the process to highlight their role as stewards of a culturally and ecologically distinctive region.

The results of our deliberative valuation process were used together with the output of a linked terrestrial and aquatic ecosystem model, itself driven by the output of a global climate model, to evaluate the relative desirability of alternative plausible futures for the UMRW. The land-use and socioeconomic scenarios we adopted are described by Thorn et al. (2017), and the coupled terrestrial and aquatic biogeophysical model and its projections are reported by Samal et al. (2017). Mavrommati et al. (2016) present the deliberative multicriteria evaluation procedure employed and its results. Here, we bring these three efforts together to provide quantitative evaluations of ecosystem service levels at the end of the 21 st century projected to result from alternative courses of action taken in the intervening years.

\section{METHODS}

\section{Study location}

The focus of our study is the UMRW in New Hampshire, USA (Fig. 1). For our study, we define the UMRW as the drainage area to a point just south of the city of Manchester (latitude: $43^{\circ} 39^{\prime}$ $27^{\prime \prime} \mathrm{N}$, longitude: $\left.71^{\circ} 30^{\prime} 2^{\prime \prime} \mathrm{W}\right)$. At this point, the watershed drains an area of $8000 \mathrm{~km}^{2}$ located entirely in the state of New Hampshire. Nearly $80 \%$ of the land in the UMRW is undeveloped forest, farm, or wetland (NHDES 2016). Partly because of its currently undeveloped nature, the upper segment is designated a National Wild and Scenic River, has good water quality, and supports at least 19 resident fish species, including 8 species of recreational importance (NHDES 2016). Because maintenance of high water quality in the Merrimack is critical to its continued use for water supply and recreation, the river is part of the New Hampshire Rivers Management and Protection Program.

The Merrimack watershed has recently been experiencing rapid population growth, leading to land-cover change, increased water withdrawals, and greater wastewater discharge (American Rivers 2016, Samal et al. 2017). Future climate change in this region is projected to increase temperature and lead to greater and more variable precipitation (Hayhoe et al. 2007, Wake et al. 2014). These dual pressures of development and climate change will affect the region's natural amenities, with concomitant effects on both winter and summer tourism and their cultural and economic values. All of these conditions make the UMRW an ideal location 
for exploring methods of predicting and evaluating changes in ecosystem service provision under alternative future scenarios.

Fig. 1. Map of the Merrimack River watershed, with the area of study indicated by darker shading. Licensed under the Creative Commons Attribution-Share Alike 2.5 Generic license.

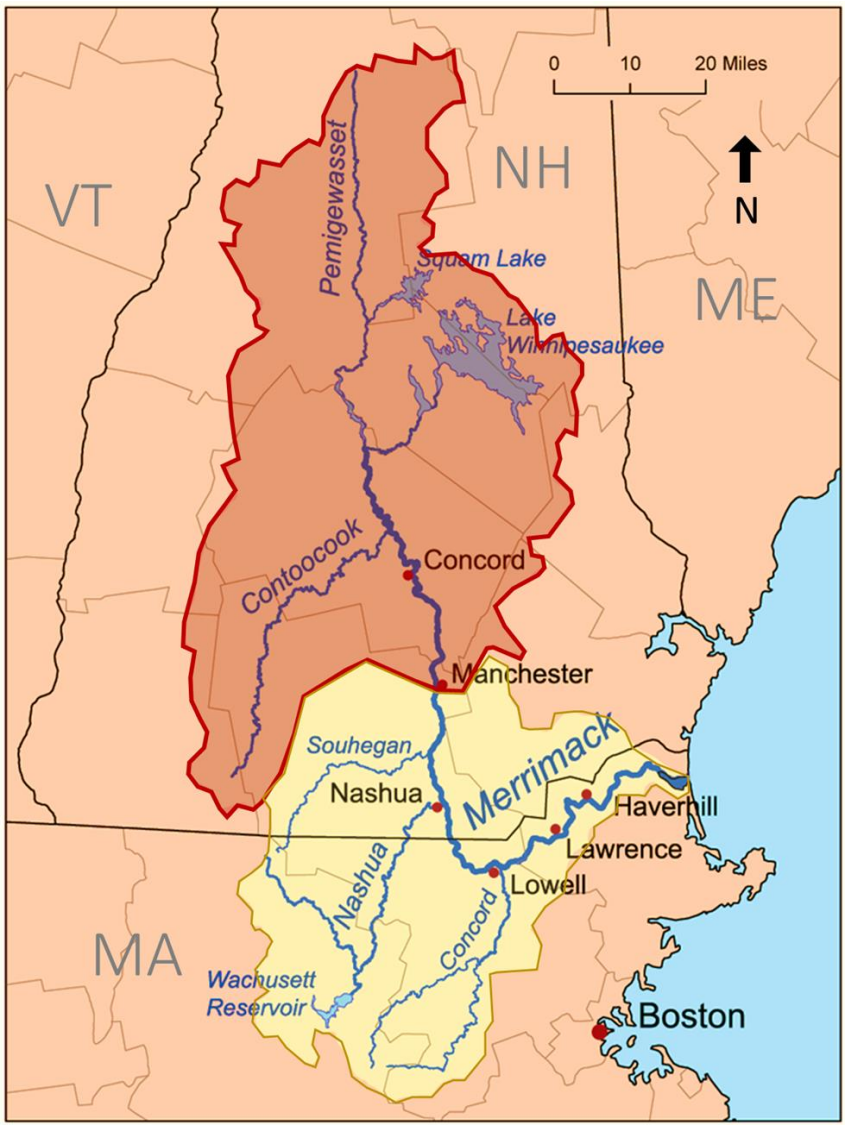

\section{Multiattribute value function}

A recent survey of the citizens of New Hampshire revealed that their primary objectives regarding watershed management include: future provision of safe drinking water, control of pollution and its effects on fish and wildlife, protection from flooding, and opportunities for recreation, among others (Rogers et al. 2014). Because of limited resources, such objectives may not all be able to be met to the greatest possible degree. A multiattribute value function is a nonmonetary method for quantifying the relative desirability of a particular state of the world, as defined over a multidimensional space of attributes characterizing the degree to which the various objectives are met (Fishburn 1967, Keeney and Raiffa 1976). In the context of our study, such a combination is the result of a particular future land use and climate scenario, and the value function conveys the overall ability of that scenario to provide a desired suite of ecosystem services, with each service weighted according to its assessed social importance. This can be written as:

$$
\begin{aligned}
& v\left(x_{1}, \ldots, x_{i}, \ldots, x_{n}\right)= \\
& w_{1} \cdot v_{1}\left(x_{1}\right)+\ldots+w_{i} \cdot v_{i}\left(x_{i}\right)+\ldots+w_{n} \cdot v_{n}\left(x_{n}\right)
\end{aligned}
$$

where each $x_{\mathrm{i}}$ is an attribute characterizing the level of one of the $n$ ecosystem services being valued, $v\left(x_{1}, \ldots, x_{\mathrm{i}}, \ldots, x_{\mathrm{n}}\right)$ is the multiattribute value function with scalar result, $w_{\mathrm{i}}$ are the importance weights for each ecosystem service attribute, and $v\left(x_{\mathrm{i}}\right)$ are single-attribute value functions that convert each attribute to a 0 to 1 scale.

We assume a linear form for the single-attribute value functions, which can be written as:

$$
v_{i}=\frac{x_{i}-x_{i}^{\text {worst }}}{x_{i}^{\text {best }}-x_{i}^{\text {worst }}}
$$

where $x_{i}{ }^{\text {worst }}$ and $x_{\mathrm{i}}^{\text {best }}$ are, respectively, the least desirable and most desirable levels of each attribute across all scenarios considered (Keeney and Raiffa 1976). This linear form, which assumes constant marginal preferences for each attribute, is used regularly as a simplification for multiattribute ecosystem service valuation (see Martin and Mazzotta [2018] for a review).

The additive form of equation (1) assumes that there are no interactions among preferences for the ecosystem services being considered. This assumption means that preferences are compensatory such that low provision of one ecosystem service can be offset by greater provision of another (Garmendia and Gamboa 2012). This assumption is consistent with the concept of weak sustainability, which allows substitution between various forms of capital, rather than strong sustainability, which regards certain types of natural capital as nonsubstitutable (Neumayer 2003). It is thus important to consider carefully the choice and definition of ecosystem services being considered. In addition to exhibiting additive independence, attributes must be mutually preference independent, meaning that preferences for specific levels of one attribute do not depend on the level of another (Keeney and Raiffa 1976). It is also useful for attributes to be mutually exclusive and collectively exhaustive so that they cover the range of key concerns without double-counting.

We relied on project scientists from diverse disciplines (e.g., aquatic ecology, forest ecology, ecological economics, and decision science) to select and define the ecosystem services to be considered. The goal was to include ecosystem services that would be both salient and important to the general public. It was also necessary that future levels of the ecosystem services could be projected for future conditions using available knowledge and models (Samal et al. 2017). Ultimately, we settled on 10 ecosystem services, with corresponding environmental indicators as attributes, that could be classified into three domains: land, climate, and water (Table 1). This classification scheme leads our final multiattribute value function to have the nested form:

$$
v_{\text {total }}=\sum_{j=1}^{m} w_{j} \cdot \sum_{i=1}^{n_{j}} w_{i} \cdot v_{i}\left(x_{i}\right)
$$

where $w_{\mathrm{j}}$ are the $m$ domain weights, and $w_{\mathrm{i}}$ are the $n_{\mathrm{j}}$ attribute weights within each domain $j$.

\section{Deliberative valuation process}

A variety of methods have been proposed for determining the trade-off weights needed in equation (1) (Von Winterfeldt and Edwards 1986). However, such methods are typically designed to 
Table 1. Ecosystem services, corresponding environmental indicators, and evaluated range (Mavrommati et al. 2016).

\begin{tabular}{|c|c|c|c|c|}
\hline Domain & Ecosystem service & Environmental indicator (average over 2070-2099) & Units & $\begin{array}{l}\text { Range used for } \\
\text { deliberative valuation }\end{array}$ \\
\hline \multirow[t]{3}{*}{ Land } & Farmland & $\begin{array}{l}\text { Total area of agricultural land (both cropland and } \\
\text { pasture) divided by population }\end{array}$ & $\mathrm{m}^{2} /$ person (acres/person) & $200-4050(0.05-1.0)$ \\
\hline & Forest Cover & Proportion of total watershed area in forest cover & $\%$ of total land area & $60-80$ \\
\hline & Forest Type & Proportion of forest suitable for maple trees & $\%$ of forest & $26-48$ \\
\hline \multirow[t]{3}{*}{ Climate } & Heat Regulation & Number of days each year with temperature $>32^{\circ} \mathrm{C}$ & $\mathrm{d} / \mathrm{yr}$ & $15-71$ \\
\hline & Snow Cover & Number of days each year with snow $>15 \mathrm{~cm}$ & $\mathrm{~d} / \mathrm{yr}$ & $7-25$ \\
\hline & Recreation Days & $\begin{array}{l}\text { Number of days each year with temperature between } \\
21 \text { and } 32^{\circ} \mathrm{C}\end{array}$ & $\mathrm{d} / \mathrm{yr}$ & $109-123$ \\
\hline \multirow[t]{4}{*}{ Water } & Fish Habitat & $\begin{array}{l}\text { Total upstream river length impaired by temperature, } \\
\text { chloride, or discharge }\end{array}$ & $\%$ river length & $10-50$ \\
\hline & Coastal Health & $\begin{array}{l}\text { Nitrogen export to estuary that exceeds regulatory } \\
\text { threshold }\end{array}$ & thousand tonnes/yr of nitrogen & $0.2-3.3$ \\
\hline & Water Supply & Population duration of water supply stress & million person-days/yr & $1.3-4.5$ \\
\hline & Flood Protection & Population duration of potential flood impact & thousand person-days/yr & $0-5$ \\
\hline
\end{tabular}

describe the preferences of an individual, and problems arise when attempting to aggregate these into social preferences. This difficulty is because individual preferences are entirely subjective and cannot be compared interpersonally (Robbins 1938). The idea behind deliberative valuation, therefore, is to aggregate preferences of individuals through a discursive process rather than through mathematical aggregation (Wilson and Howarth 2002, Howarth and Wilson 2006, Proctor and Drechsler 2006, Kenter et al. 2011). Small groups of citizens are brought together to discuss the relative importance of a particular set of ecosystem services. In the process, participants have the opportunity to think deeply about their own preferences and engage with others about alternative perspectives of knowledge, beliefs, and values (Kenter et al. 2016b). This forum also provides an opportunity to obtain additional information as needed from subject-matter experts on the economic or environmental systems being considered. The goal is for the group to reach an informed, collective judgement based on shared social values rather than simply their individual preferences (Wilson and Howarth 2002).

Kenter et al. (2016b) recognize many factors that may influence the outcome of deliberative valuation, including process design and facilitation, group composition, and extent of exposure to new information. They use this recognition to develop a six-step template for designing a deliberative valuation process. The six steps include: (1) establishment of the institutional context, including possible actions; (2) deliberation on transcendental values; (3) expression of contextual beliefs, broader policy impacts, and systemic relations; (4) consideration of the implications of possible actions on transcendental values; (5) discussion of norms and contextual values; and (6) establishment of value indicators (Kenter et al. 2016b). While our study design preceded the publication of Kenter et al.'s (2016b) template, we followed a similar process, as described below. Details on participant recruitment, the deliberative valuation exercise, and full results are reported by Mavrommati et al. (2016). Here, we describe only the components of the study relevant to determination of the trade-off weights in our multiattribute value function.

To assess the relative importance of the 10 ecosystem services (Table 1), we held full-day workshops with residents of the
UMRW on four dates in September 2015. Of the 217 willing and eligible participants recruited through local media, we selected 96 that approximately represented the demographics of the New Hampshire population by age, sex, income, and political affiliation (see Mavrommati et al. 2016). These were each assigned to one of the four dates, and 67 of the invitees actually attended. Based on the number of attendees at each workshop, we formed two groups on the first date and three on each of the remaining dates, with each group comprising between five and seven participants. Participants received coffee and pastries, lunch, travel cost reimbursement, and $\$ 100$ as compensation for their involvement in our study.

The morning of each workshop was spent by introducing participants to the ecosystem services concept, the deliberative process, and the nature of their valuation task. In the afternoon, participants were divided into groups, and each group met in a separate room. Each group then performed the choice tasks described by Mavrommati et al. (2016). These tasks involved the comparative valuation of various combinations of different levels of the ecosystem services within each of the three domains (Table 1), as well as comparisons across the three domains. In the morning introduction, as well as throughout the deliberative process, participants were asked to consider themselves as trustees for inhabitants of the UMRW in the year 2100 and therefore to consider explicitly the needs and preferences of future generations in their valuations. A professional facilitator managed the discussions of each group to keep the participants on task and to encourage full group participation. Scientists representing each of the three domains were also available to answer any questions participants may have had about the ecosystem services being considered.

From the results of the choice tasks, trade-off weights on each ecosystem service for each of the 11 groups were calculated as described by Mavrommati et al. (2016). All participants also completed individual preference surveys both before and after the group deliberations. These individual preferences are not discussed here, but are evaluated by Murphy et al. (2017).

The range of attribute levels used in the deliberative valuation process (Table 1) were derived from projections of scenarios 
Table 2. Socioeconomic and land-cover scenarios (2070-2099).

\begin{tabular}{|c|c|c|c|c|c|c|c|}
\hline \multirow{2}{*}{$\begin{array}{l}\text { Land-use scenario of } \\
\text { Thorn et al. (2017) }\end{array}$} & \multirow{2}{*}{$\begin{array}{l}\text { Scenario } \\
\text { designation }\end{array}$} & \multicolumn{3}{|c|}{ Socioeconomic factors } & \multicolumn{3}{|c|}{ Proportion of land cover (\%) } \\
\hline & & Population & $\begin{array}{l}\text { Development } \\
\text { patterns }\end{array}$ & Water management & Forest & Farm & Developed \\
\hline Linear Trends & LT & 639,000 & Current trends & $\begin{array}{l}\text { Moderate expansion of traditional } \\
\text { infrastructure; most residents } \\
\text { depend on wells and septic systems }\end{array}$ & 77 & 4 & 5 \\
\hline Backyard Amenities & BA & 975,000 & $\begin{array}{l}\text { Dispersed } \\
\text { residential } \\
\text { development }\end{array}$ & $\begin{array}{l}\text { Increased reliance on wells and } \\
\text { septic systems }\end{array}$ & 64 & 3 & 26 \\
\hline $\begin{array}{l}\text { Large Community }+ \\
\text { Wildlands }\end{array}$ & $\mathrm{LCW}$ & 975,000 & $\begin{array}{l}\text { Concentrated } \\
\text { mixed-use } \\
\text { development, } \\
\text { conservation of } \\
\text { forest land }\end{array}$ & Expansion of green infrastructure & 80 & 5 & 5 \\
\hline $\begin{array}{l}\text { Small Community + } \\
\text { Food }\end{array}$ & $\mathrm{SCF}$ & 380,000 & $\begin{array}{l}\text { Concentrated } \\
\text { development, } \\
\text { increased local } \\
\text { agriculture }\end{array}$ & $\begin{array}{l}\text { Moderate expansion of green } \\
\text { infrastructure; improved } \\
\text { agricultural nutrient management }\end{array}$ & 64 & 20 & 5 \\
\hline
\end{tabular}

believed to be extreme cases before our final scenarios were developed. Given the additive form of our value function, the magnitude of the assessed weight $w_{\mathrm{i}}$ of any particular attribute $i$ should be dependent on the width of the range and $x_{i}^{\text {worst }}$ and $x_{i}^{\text {best }}$ for that attribute. Presumably, the wider the difference between the worst and best possible levels of an attribute, the greater the weight one would put on that attribute (Keeney and Raiffa 1976). As the projected ranges for our actual final scenarios differed somewhat from those used in the workshops, we rescaled the workshop-derived weights before final scenario valuation according to the expression:

$$
w_{i}=w_{i}^{*} \cdot\left(\frac{x_{i}^{\text {best }}-x_{i}^{\text {worst }}}{x_{i}^{\text {best* }}-x_{i}^{\text {worst }}}\right)
$$

where $w_{\mathrm{i}}{ }^{*}$ are the workshop-derived weights; $x_{\mathrm{i}}^{\text {best* }}$ and $x_{\mathrm{i}}{ }^{\text {worst* }}$ are the best and worst attribute levels, respectively, presented to the participants; and $x_{\mathrm{i}}^{\text {best }}$ and $x_{\mathrm{i}}{ }^{\text {worst }}$ are the best and worst attribute levels, respectively, across the final scenarios. These rescaled weights were then normalized by dividing by the sum of rescaled weights across each domain. For these reasons, the weights we present differ somewhat from those reported by Mavrommati et al. (2016). For our scenario valuations, we use the average of weights across groups and investigate the implications of this assumption through sensitivity analysis.

\section{Scenarios considered}

Scenarios are a common method for considering the effect of alternative futures on ecosystem service values (Bohensky et al. 2011, Sandhu et al. 2018). To evaluate a range of possible futures for the UMRW, we considered combinations of two climate scenarios and four socioeconomic and land-cover scenarios. The two climate scenarios were chosen to represent potential regional extremes and correspond to Intergovernmental Panel on Climate Change scenarios $\mathrm{B} 1$ (atmospheric $\mathrm{CO}_{2}$ concentration of $550 \mathrm{ppm}$ by 2100 , which we label "low") and A1FI (970 ppm $\mathrm{CO}_{2}$, labelled "high"). Socioeconomic and land-cover scenarios described by
Thorn et al. (2017) were then used to reflect alternative assumptions about land cover, population, economic growth, water infrastructure, policy, and transportation (Table 2). These scenarios synthesized the perspectives and expertise of diverse stakeholders in New Hampshire and provide the quantitative information and hypothetical land-cover maps needed by the simulation models to project the ecosystem services provided by the watershed at the end of the century.

In generating the scenarios, Thorn et al. (2017) made three distinct sets of assumptions regarding future population growth, policy goals, and development patterns. The Linear Trends (LT) scenario family assumes linear extrapolation of the land-cover and conservation patterns observed from 1996 to 2011, linear extrapolation of the population growth observed from 1990 to 2010, and a regulatory environment similar to the present day. The Backyard Amenities (BA) family of scenarios assumes rapid population growth, dispersed development consisting primarily of single family homes on 4000 to $8000 \mathrm{~m}^{2}$ (1-2 acre) lots, and little regulation or public effort to conserve land. Finally, the Community Amenities scenarios assume primarily concentrated, mixed-use development with an emphasis on conservation of existing forest and agricultural land. Within the Community Amenities scenario family, Thorn et. al (2017) consider two additional sets of assumptions for population growth and landcover change: either high population growth comparable to the Backyard Amenities scenarios ("Large") or slight population reductions ("Small"), and either conservation of present day forest cover ("Wildlands") or an emphasis on local agriculture, promotion of local foods, and a corresponding increase in agricultural land ("Food"). For simplicity here, we consider only the pairing of high population growth and forest protection (Large Community + Wildlands [LCW]) and low population growth and expansion of local agriculture (Small Community + Food [SCF]; Table 2). Detailed scenario descriptions as well as maps of projected future land cover and population density simulations are provided by Thorn et al. (2017). 
Fig. 2. Trade-off weights in each domain and across domains as estimated from the deliberative valuation workshops and rescaled to account for the range of attribute levels across the eight scenarios.

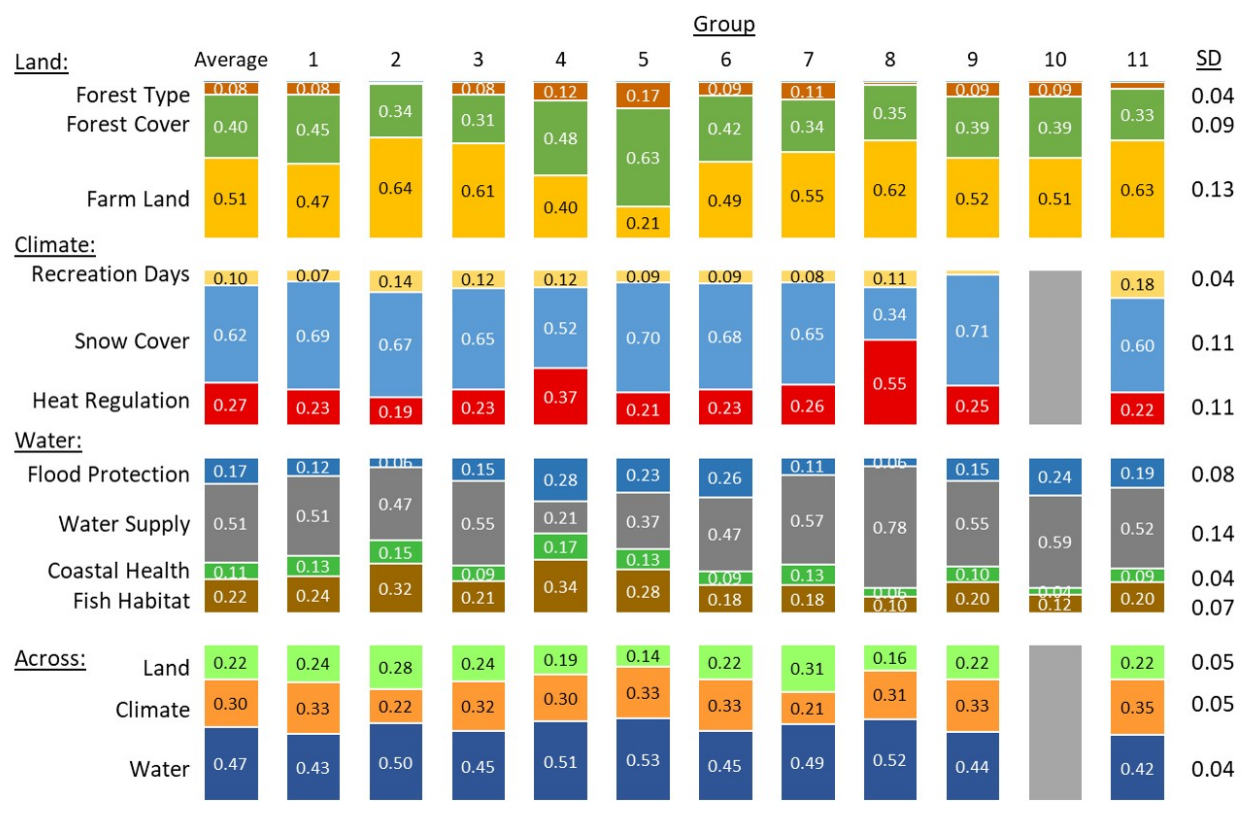

\section{Scenario projections}

Pairing each of the four socioeconomic and land-cover scenarios with each of two climate scenarios gives a total of eight scenarios to be considered. These scenarios were translated into levels of the environmental indicators using multiple methods. Terrestrial indicators were derived directly from the land-cover scenarios (Thorn et al. 2017) and the Northern Research Station Climate Change Atlas (Iverson et al. 2008). Climate indicators were derived from the results of global climate models downscaled to the Franklin, New Hampshire meteorological station, as described by Wake et al. (2014). Hydrological and water quality indicators were simulated by coupling forest (PnET-CN) and aquatic (FrAMES) process-based models. This coupled terrestrial and aquatic model is especially appropriate for forest-dominated watersheds because it explicitly accounts for forest processes, terrestrial-aquatic linkage, in-stream processing, and nitrogen loading (Samal et al. 2017).

Any model inputs or parameters expected to be responsive to climate or human development were modified to be consistent with the assumptions of each scenario. Model inputs related to climate were derived from the Geophysical Fluid Dynamics Laboratory CM2.1 model statistically downscaled by Hayhoe et al. (2007). Key climate drivers for the coupled model include average, minimum, and maximum daily air temperature; total daily precipitation; average daily cloud cover; and average daily wind speed. Key model parameters modified in response to landcover assumptions include imperviousness (affecting flow regime, total runoff), road salt application rates (affecting water quality), suburban and agricultural nonpoint source loads, and waste water treatment plant point loads. Specific parameterizations and a description of how they were varied according to each scenario are provided by Samal et al. (2017).

\section{RESULTS}

\section{Ecosystem service trade-off weights}

In our workshops, all groups but one were able to reach consensus on the various choice tasks leading to ecosystem service trade-off weights. Group 10 could not agree on the relative importance of attributes within the climate domain or on the trade-offs across the three domains. For all other groups, the pattern of trade-off weights across many of the attributes and domains was reasonably similar, as indicated by low standard deviations (Fig. 2).

In the Land domain, for example, 9 of 11 groups placed the greatest weight on Farm Land, with an overall average weight $(\hat{w})$ of 0.51 across groups. Many participants argued that local farms may provide food security, in addition to health, cultural, and aesthetic benefits. Groups 4 and 5 were the exception, giving greater weight to forest cover, which has $\hat{w}=0.40$ across groups. Here, participants recognized the connections between forest cover, carbon sequestration, and overall ecosystem health. They also appreciated the recreational opportunities that would be provided by forests in the watershed. Although maple is an iconic tree species in New England, Forest Type was deemed much less important by all groups $(\hat{\mathrm{w}}=0.08)$, likely because of the relatively small differences in projected values for this attribute across scenarios (Table 3 ). 
Table 3. Predicted levels of environmental indicators in the upper Merrimack River watershed for each land-cover and climate scenario in 2070-2099 (Samal et al. 2017). Scenarios: low = low emissions, high $=$ high emissions, acronyms defined in Table 2.

\begin{tabular}{|c|c|c|c|c|c|c|c|c|c|c|}
\hline \multirow[t]{2}{*}{ Scenario } & \multicolumn{3}{|c|}{ Land } & \multicolumn{3}{|c|}{ Climate } & \multicolumn{4}{|c|}{ Water } \\
\hline & $\begin{array}{l}\text { Farmland } \\
{\left[\mathrm{m}^{2} /\right.} \\
\text { person } \\
\text { (acres/ } \\
\text { person)] }\end{array}$ & $\begin{array}{c}\text { Forest } \\
\text { cover }(\% \text { of } \\
\text { total land } \\
\text { area) }\end{array}$ & $\begin{array}{l}\text { Forest } \\
\text { type ( } \% \\
\text { of } \\
\text { forest) }\end{array}$ & $\begin{array}{l}\text { Heat } \\
\text { regulation } \\
\text { (extreme } \\
\text { hot } \mathrm{d} / \mathrm{yr} \text { ) }\end{array}$ & $\begin{array}{l}\text { Snow cover } \\
(\mathrm{d} / \mathrm{yr})\end{array}$ & $\begin{array}{l}\text { Recreation } \\
\text { days }(\mathrm{d} / \mathrm{yr})\end{array}$ & $\begin{array}{l}\text { Fish habitat } \\
\text { (\% river } \\
\text { length } \\
\text { impaired) }\end{array}$ & $\begin{array}{l}\text { Coastal } \\
\text { health } \\
\text { (thousand } \\
\text { tonnes/yr } \\
\text { excess } \\
\text { nitrogen) }\end{array}$ & $\begin{array}{l}\text { Water supply } \\
\text { (million } \\
\text { person-days/ } \\
\text { yr) }\end{array}$ & $\begin{array}{c}\text { Flood } \\
\text { protection } \\
\text { (thousand } \\
\text { person-days/yr } \\
\text { flooding) }\end{array}$ \\
\hline LT_low & $\begin{array}{c}566 \\
(0.14)\end{array}$ & 77 & 34 & 16 & 47 & 114 & 5 & 0.18 & 0.6 & 2.1 \\
\hline BA_low & $\begin{array}{c}283 \\
(0.07)\end{array}$ & 64 & 34 & 16 & 47 & 114 & 13 & 0.48 & 7.3 & 7.0 \\
\hline LCW_low & $\begin{array}{c}445 \\
(0.11)\end{array}$ & 80 & 34 & 16 & 47 & 114 & 5 & 0.65 & 0.9 & 5.1 \\
\hline SCF_low & $\begin{array}{c}4087 \\
(1.01)\end{array}$ & 64 & 34 & 16 & 47 & 114 & 6 & 0.05 & 0.8 & 1.8 \\
\hline LT_high & $\begin{array}{c}566 \\
(0.14)\end{array}$ & 77 & 29 & 46 & 18 & 105 & 30 & 0.86 & 0.4 & 3.7 \\
\hline BA_high & $\begin{array}{c}283 \\
(0.07)\end{array}$ & 64 & 29 & 46 & 18 & 105 & 40 & 1.00 & 6.0 & 4.8 \\
\hline LCW_high & $\begin{array}{c}445 \\
(0.11)\end{array}$ & 80 & 29 & 46 & 18 & 105 & 27 & 1.36 & 0.6 & 7.7 \\
\hline $\mathrm{SCF}_{-}$high & $\begin{array}{l}4087 \\
(1.01)\end{array}$ & 64 & 29 & 46 & 18 & 105 & 29 & 0.55 & 0.6 & 3.2 \\
\hline
\end{tabular}

Of the Climate attributes, Snow Days was judged most important by most groups $(\hat{\mathrm{w}}=0.06)$, who recognized the recreational and economic costs in New Hampshire if the number of snow days were to decrease. They also judged there to be a link between future snow cover and ecosystem health. Heat Regulation followed, with $\hat{\mathrm{w}}=0.27$, supported by arguments related to the future effects on human health, labor productivity, and cooling requirements. All groups judged that Recreation Days, an indicator of mild temperatures, is the least important attribute given the small range between the lowest and highest values projected across scenarios (Table 3 ).

In the Water domain, the average weights on Flood Protection and Coastal Health were both low. In the case of the former, most participants stated a belief there would be future capacity to reduce flood risk through appropriate land-use and mitigation measures. In the case of the latter, coastal indicators were believed to have less direct consequence to human well-being. Water Supply received a substantially higher weight from all groups except group 4, whereas Fish Habitat was of intermediate importance. Finally, across the three domains, all groups gave greater weight to Water than to Climate or Land, arguing that water was fundamental to future human health and well-being.

\section{Effects of scenarios on social value}

The projected levels of environmental indicators in 2070-2099 span the range of what is considered plausible for ecosystem service provision under the specified land-use and climate scenarios (Table 3). The overall social value of the ecosystem services provided under each scenario then depends on the combination of projected indicator levels and citizen stakeholder weights (Fig. 3A). Based on the average weights, the LT and Community Amenities land-use assumptions paired with low greenhouse gas emissions (LT_low, LCW_low, and SCF_low, respectively) have the highest assessed social value. The BA, low climate change scenario (BA_low) has substantially lower social value, primarily because of reductions in the land and water domains.

Compared to low emissions scenarios, high emissions scenarios show the same relative patterns with land use but with substantial declines in total social value (Fig. 3A). This is because in the high emissions scenarios, climate attributes are each at their most undesirable projected levels, thus contributing no positive social value (Fig. 3C). More specifically, under the low emissions scenarios, the multiyear mean number of days $>32^{\circ} \mathrm{C}$ is projected to increase to $16 \mathrm{~d} / \mathrm{yr}$ by 2100 , whereas under the high emissions scenario, this contribution to heat stress increases to $46 \mathrm{~d} / \mathrm{yr}$ (Table 3). Also, compared to the projected mean of $47 \mathrm{~d} / \mathrm{yr}$ with $>15 \mathrm{~cm}$ of snow under the low emissions scenario, the reduction under the high emissions scenarios to $18 \mathrm{~d} / \mathrm{yr}$ is substantial. The number of comfortable spring and summer recreation days differs relatively little between the scenarios (115 and $105 \mathrm{~d}$ under the low and high emission scenarios, respectively) because the increase in the number of days that were previously too cool is expected to be approximately compensated by a reduction in comfortable recreation days caused by an increase in days that are too hot. This gives the Recreation Days indicator little importance in overall social value (Fig. 3C).

The contributions to total social value of ecosystem services in the land domain (Fig. 3B) result directly from the scenario narratives and land-cover change modeling. For example, in the BA land-cover scenarios, forest cover is assumed to decline from the present $80 \%$ to $64 \%$ by 2100 to accommodate increased suburban development. In the Community Amenities scenarios, the present forest cover is either maintained (LCW) or replaced by increased farmland (SCF). Together with a population increase 
Fig. 3. Overall multiattribute social value of each scenario subdivided by domain (A), as well as the relative contribution of ecosystem services within each domain for land (B), climate (C) and water (D). The least desirable levels of each attribute have, by definition, zero contribution to multiattribute social value. Scenarios: low $=$ low emissions, high $=$ high emissions, acronyms defined in Table 2.
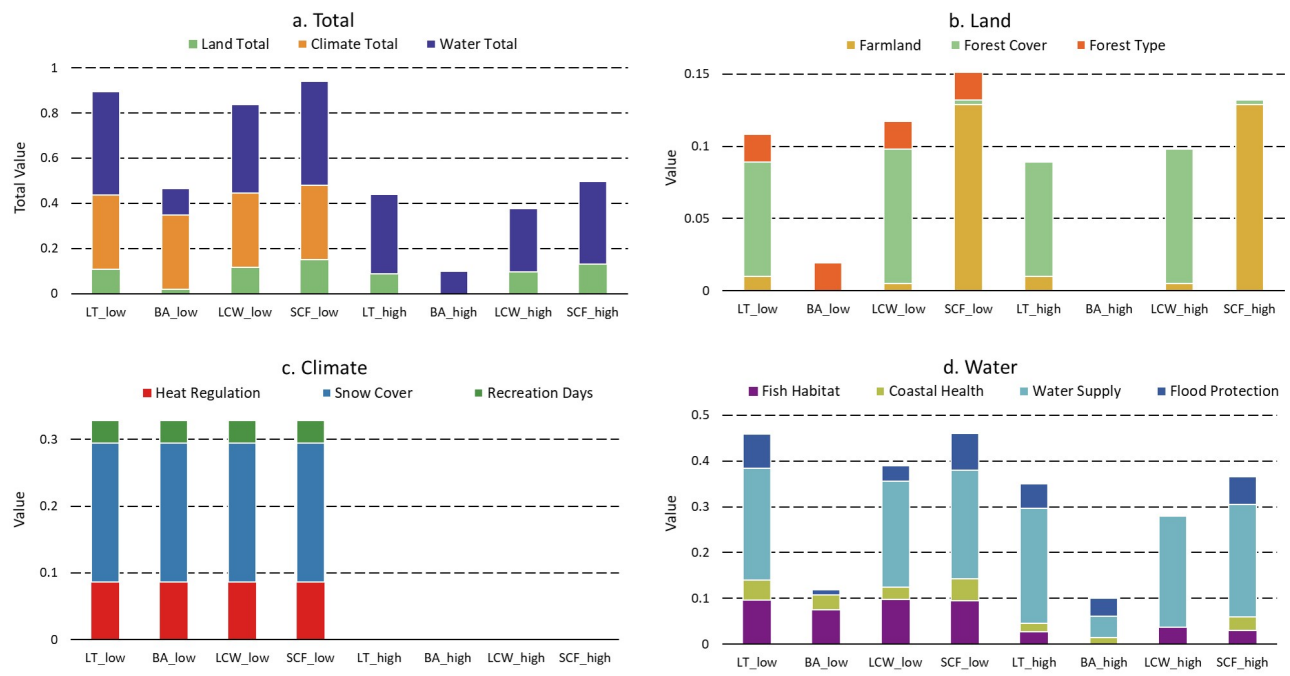

of $170 \%$ by 2100 in the BA and LCW scenarios and a decline of $5 \%$ in the SCF scenarios, this leads to large differences in the amount of farmland per person 283 vs. $4046 \mathrm{~m}^{2}$ ( 0.07 vs. 1.0 acre). The relatively high contribution of farmland to the social value function reflects these large differences. The Forest Type indicator, which represents the suitability for maple forest, is linked primarily to the climate factor in scenario definitions. Compared to comprising $49 \%$ of total forest cover currently, it is projected to be reduced by 2100 to $29 \%$ in the high emissions scenarios and $34 \%$ in the low emissions scenarios.

The contributions of water-related ecosystem services to overall social value (Fig. 3D) reflect scenario projections concerning both climate and land use. The hydrological and biogeochemical processes in the watershed are primarily driven by climate factors. However, these processes are mediated by land-cover changes, including impervious surface and population density, which affect vegetation growth, evapotranspiration, and water residence time (Samal et al. 2017). The differences in the relative effects of climate and land-use changes across the water indicators lead to some interesting trade-offs in the provision of aquatic ecosystem services across the scenarios (Fig. 3D). For example, Fish Habitat is seen to be dominated by climate change because impairment is greater across all land-cover scenarios for the high emissions scenarios than for the corresponding low emissions scenarios. Samal et al. (2017) indicate that this result is primarily related to substantial temperature impairment in headwater streams. Specific land-use assumptions then only slightly modify the impairments caused by climate change. For example, residential development and the associated increase in impervious surfaces under the BA land-use scenario cause $10 \%$ more of the total stream length to violate either flow, temperature, or chloride criteria by 2100 . In contrast, under the Community Amenities scenarios, concentrated development and green infrastructure result in negligible additional habitat impairment relative to the linear extrapolation of current trends under both projected emissions scenarios.

The Coastal Health indicator, as measured by nitrogen load to the estuary in excess of coastal criteria, is much worse than present day under all scenarios, with climate as the primary driver and land-use effects being secondary. High emissions scenarios result in greater coastal nitrogen flux than do low emissions scenarios because of greater overall loading from all land-cover types, including forests that are becoming more temperature stressed (Samal et al. 2017), as well as reduced nitrogen retention capacity of the river system (Wollheim et al. 2008). In the BA and SCF scenarios, for example, excess nitrogen load increases to $>1000$ tons/yr of nitrogen. Under the corresponding low emissions scenarios, however, excess nitrogen export is projected to be only $50-60$ tons/yr of nitrogen. The SCF land-use scenarios have relatively lower values because of the assumptions of a lower population and improved fertilizer management. Despite the relatively large changes in this ecosystem service, however, the lower assessed weight (Fig. 2) means that it does not substantially contribute to the different values across scenarios.

Water Provision is one of the few ecosystem services in the UMRW that is expected to improve with greater climate change. The population duration of water supply stress is approximately $20-40 \%$ lower under the high vs. low emissions scenarios because of increased precipitation and greater forest water-use efficiency under a carbon-enriched atmosphere (Samal et al. 2017). In both cases, the BA land-use scenarios have the greatest water supply stress (6000 to 7300 person-days/yr), largely due to the assumption of a greater population. 
While the projection of increased precipitation in the UMRW may help to alleviate water supply stresses, it implies a potential for worsened flooding under more severe climate change. However, because of the population and land-use assumptions we made, this change is only partly true. For the LT, LCW, and SCF land-use scenarios, flood risk is $50-80 \%$ higher under the high than low emissions scenario, and within these scenarios it is largely proportional to the assumed watershed population. However, for the BA scenarios, flood risk is actually $30 \%$ lower under the high than low emissions scenario. This is because, while in the LCW scenarios it is assumed that population growth will be concentrated in existing downstream urban areas, in the BA scenarios, this population is much more spread out across the watershed, including in northern headwater regions less susceptible to flooding (Thorn et al. 2017).

When viewed in totality, the combination of model projections and trade-off weights compared across scenarios reveals that Water Supply and Snow Cover have the greatest influence on overall ranking (Fig. 4). Those scenarios lacking one or the other of these ecosystem services have substantially lower values than those able to provide both. Of the latter, the major difference is the trade-off associated with conservation of forest cover or expansion of agriculture. Both uses are seen as important by the citizen stakeholders but are generally in conflict with one another. As noted earlier, climate differences among scenarios have much stronger influence than land-use differences, with nearly all high emissions scenarios being less desirable than even the lowest scoring low emissions scenario. Only SCF_high is able to compensate for the loss of snow days and greater heat stress relative to BA_low with more farmland and greater water supply.

Fig. 4. Overall multiattribute value of each scenario, including the relative contribution of each ecosystem service. Scenarios: low $=$ low emissions, high $=$ high emissions, acronyms defined in Table 2.

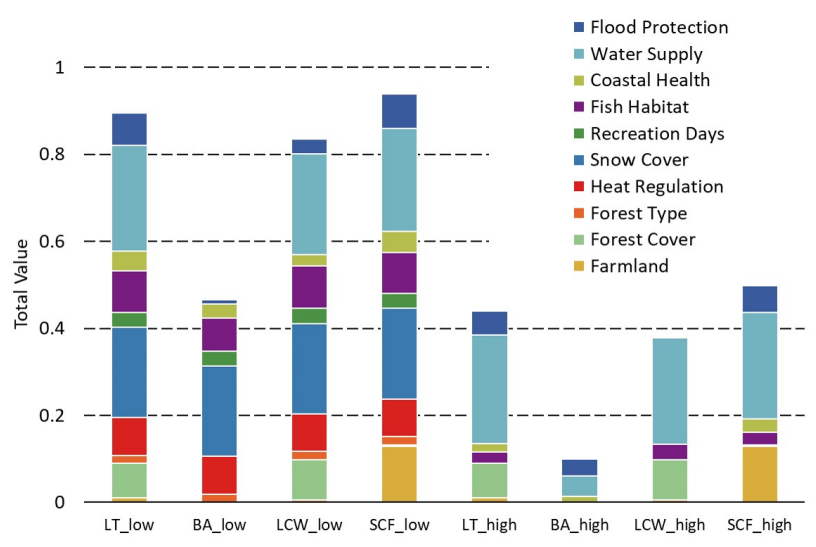

\section{DISCUSSION}

Deliberative ecosystem service valuation provides a means for improving mutual stakeholder respect and understanding, capturing shared values, and describing the relative desirability of alternative courses of action (Wilson and Howarth 2002). However, previous applications of deliberative valuation have mostly focused on social preferences over the aggregate outcome of actions or decisions rather than on the relative importance of specific ecosystem services (Spash 2007, Lo and Spash 2013, Kenter et al. 2016a). For decisions in the public sector to be defensible and transparent, the task of articulating preferences for varying levels of ecosystem service provision should be separated from the task of projecting the levels that would be provided under alternative courses of action. In analyses for which this separation has occurred, projections of future attribute levels have typically been performed using expert judgement, not quantitative models (e.g., Proctor and Drechsler 2006, Randhir and Shriver 2009, Kenter 2016, Orchard-Webb et al. 2016). Our study exemplifies how ecosystem and climate models can be used along with deliberative valuation and scenario analysis to evaluate rigorously the relative desirability of alternative futures.

We found that climate change has a greater potential to affect the value of the UMRW's ecosystem services to its future inhabitants than do land or water management decisions. The projected loss of snow cover days, in particular, is expected to be of great consequence to the watershed's future inhabitants. This is not surprising given the economic, cultural, and recreational importance of winter activities in New Hampshire. Comparing scenarios also reveals significant indirect effects of climate change on coastal health, riverine fish habitat, and maple forests. Unfortunately, averting global climate change is mostly beyond the control of local, regional, and state planners. Their primary leverage point for mitigating ecosystem service losses is land and water management. Although the Community Amenities and LT land-use assumptions are both more desirable than the BA assumptions under either climate change scenario, decision makers could compensate for the loss of snow days, greater heat stress, and other losses expected to occur under the worst-case scenario (BA_high) only by simultaneously fostering concentrated development and promoting local agriculture (SCF_high). This compensation comes from the amenities provided by local farms and improved water supply. Regarding water management, the deliberative valuations combined with FrAMES-PnET modeling results suggest that future UMRW inhabitants will be most satisfied if managers in the intervening years prioritize water supply over flood protection and concentrate on riverine fish habitat more than coastal health. These priorities are consistent with the geographic positioning of the UMRW at the headwaters of the greater Merrimack River system (Fig. 1).

The premise of our recommendations is that the quantitative measures of ecosystem service values resulting from our deliberative valuation process represent a consensus opinion that captures the common good, rather than simply aggregating a collection of personal preferences. This assumption was supported by Murphy et al. (2017), who compared the group rankings against the results of applying a variety of aggregation methods to the individual participant preferences elicited both before and after the deliberations. For the majority of our groups, the consensus rankings could not have been predicted from individual predeliberation rankings using any of the tested aggregation methods. However, individual postdeliberation rankings could be used to reconstruct the group rankings using consensus-based aggregation rules. This implies that the participants changed their preferences as a result of the 
deliberative process and that the group preferences reflect a consensus, rather than simply the tallied preferences of the majority. Irvine et al. (2016) suggest that this ability to translate preformed individual values to the formation of shared values may lead to "more robust, inclusive and far-sighted decision making."

The observation by Murphy et al. (2017) that individual preferences changed over the course of the deliberation to represent the group consensus opinion better raises the question of how long such a new appreciation of shared social values may persist. It also invites the question of whether residents of the UMRW who do not have the opportunity to participate in such deliberations would similarly agree to a characterization of shared values that may not necessarily agree with their personal preferences (Irvine et al. 2016). Unfortunately, our study design did not enable us to follow up with participants after they left the workshops to address these questions.

Our valuation of scenarios used trade-off weights that represented the average across the 11 groups. While many groups' results were similar, there was also some variation, especially in the Land domain (Fig. 2). Sensitivity analysis to these weight differences revealed idiosyncratic changes to overall valuations, but broad patterns remained consistent, perhaps because of the relatively large differences across scenarios (Fig. 4). Further investigation of the range of preferences formed by different groups and the factors that affect such group preferences is warranted (see Mavrommati et al. 2016).

The form of our value function requires the rather strong assumptions of additivity and preference independence (Martin and Mazzotta 2018). Although these assumptions are often employed for simplicity, there are many situations in which they would obviously be violated. Any situation in which provision of one ecosystem service obviates the value of another or in which multiple ecosystem services must be provided simultaneously to produce value would not conform with the additive assumption. Langhans and Lienert (2016) tested the usual assumptions employed in multiattribute value modeling in the context of river rehabilitation by carrying out detailed elicitations with river ecologists and engineers. They found that the suitability of various simplifying assumptions depended on the individual being elicited and the current ecological state of the river, but that there was often evidence supporting a more complex representation of preferences, such as nonlinear value functions and multiplicative aggregation (Langhans and Lienert 2016).

The subjects whose preference were elicited by Langhans and Lienert (2016) were scientific experts with detailed knowledge of the ecological processes and interactions of the river system. It may be that the assumptions of linearity and additivity are more reasonable for describing the preferences of the general public or nonexpert stakeholders. However, if we are trying to describe the shared values of a group in a way that captures such complex concerns as justice, shared responsibility, and collective meaning, it is likely we will need to employ more complex mathematical representations. Indeed, the framing of relational values emphasizes the potential for collective flourishing and selflimitation of consumption, ideas that run counter to the oppositional connotations of trade-off weights and inherently more-is-better impulse of linear value functions. Recent research on the suitability of various mathematical forms for describing individual preferences (Langhans and Lienert 2016, Martin and Mazzotta 2018) should be extended to understand better how to describe shared values.

Finally, although we do not translate the values of ecosystem services into monetary terms, had we included one or more monetary attributes (e.g., cost of water treatment, timber income), we could have used the resulting multiattribute value function to calculate the equivalent monetary value of changes in other attributes. This would yield willingness-to-pay estimates that could then be used to validate the trade-off weights or provide comparisons against more conventional ecosystem service valuation studies.

\section{CONCLUSION}

We employed a combination of deliberative multicriteria evaluation, scenario analysis, climate projection, and terrestrial and aquatic ecosystem modeling to evaluate the relative desirability of alternative population, land-use, and climate change scenarios to future inhabitants of the UMRW. Our results indicate that, across scenarios, climate change has a greater potential to affect ecosystem service values than do population growth or land-use decisions. This difference is because of the expected loss of snow cover, increase in the hottest summer days, and indirect effects of climate change on aquatic and forest ecosystems. However, because local, regional, and state planners have relatively little ability to avert these climate impacts, mitigating overall ecosystem service loss means making land-use and water management decisions that align with public priorities. According to our assessment, this means concentrating future development to protect water supply and conserve or expand forest cover and farmland.

Responses to this article can be read online at: http://www.ecologyandsociety.org/issues/responses. php/10806

\section{Acknowledgments:}

This work was supported by National Science Foundation's Research Infrastructure Improvement Award EPS1101245 and by the U.S. Environmental Protection Agency's Science to Achieve Results (STAR) Award 836169. The citizens' workshops were approved by Dartmouth College IRB \#STUDY00028709, and we appreciate the involvement of 67 participants.

\section{LITERATURE CITED}

American Rivers. 2016. America's most endangered rivers: 2016. American Rivers, Washington, D.C., USA. [online] URL: https:// s3.amazonaws.com/american-rivers-website/wp-content/ uploads/2016/02/20135708/MER2016_FullReport.pdf

Bohensky, E., J. R. A. Butler, R. Costanza, I. Bohnet, A. Delisle, K. Fabricius, M. Gooch, I. Kubiszewski, G. Lukacs, P. Pert, and E. Wolanski. 2011. Future makers or future takers? A scenario analysis of climate change and the Great Barrier Reef. Global Environmental Change 21(3):876-893. http://dx.doi.org/10.1016/ j.gloenvcha.2011.03.009 
Castro, A. J., C. C. Vaughn, M. García-Llorente, J. P. Julian, and C. L. Atkinson. 2016a. Willingness to pay for ecosystem services among stakeholder groups in a south-central U.S. watershed with regional conflict. Journal of Water Resources Planning and Management 142(9):05016006. https://doi.org/10.1061/(ASCE) WR.1943-5452.0000671

Castro, A. J., C. C. Vaughn, J. P. Julian, and M. García-Llorente. 2016b. Social demand for ecosystem services and implications for watershed management. Journal of the American Water Resources Association 52(1):209-221. https://doi.org/10.1111/1752-1688.12379

Cebrián-Piqueras, M. A., L. Karrasch, and M. Kleyer. 2017. Coupling stakeholder assessments of ecosystem services with biophysical ecosystem properties reveals importance of social contexts. Ecosystem Services 23:108-115. http://dx.doi.org/10.1016/ j.ecoser.2016.11.009

Chan, K. M. A., P. Balvanera, K. Benessaiah, M. Chapman, S. Díaz, E. Gómez-Baggethun, R. Gould, N. Hannahs, K. Jax, S. Klain, G. W. Luck, B. Martín-López, B. Muraca, B. Norton, K. Ott, U. Pascual, T. Satterfield, M. Tadaki, J. Taggart, and N. Turner. 2016. Opinion: Why protect nature? Rethinking values and the environment. Proceedings of the National Academy of Sciences 113(6):1462-1465. http://dx.doi.org/10.1073/pnas.1525002113

Costanza, R. 2000. Social goals and the valuation of ecosystem services. Ecosystems 3(1):4-10. http://dx.doi.org/10.1007/s100210000002

Costanza, R., and C. Folke. 1997. Valuing ecosystem services with efficiency, fairness, and sustainability as goals. Pages 49-70 in G. C. Daily, editor. Nature's services: societal dependence on natural ecosystems. Island Press, Washington, D.C., USA.

Costanza, R., A. Voinov, R. Boumans, T. Maxwell, F. Villa, L. Wainger, and H. Voinov. 2002. Integrated ecological economic modeling of the Patuxent River watershed, Maryland. Ecological Monographs 72(2):203-231. http://dx.doi.org/10.1890/0012-9615 (2002)072[0203:IEEMOT]2.0.CO;2

Fishburn, P. C. 1967. Methods of estimating additive utilities. Management Science 13(7):435-453. https://doi.org/10.1287/ mnsc.13.7.435

Fontana, V., A. Radtke, V. B. Fedrigotti, U. Tappeiner, E. Tasser, S. Zerbe, and T. Buchholz. 2013. Comparing land-use alternatives: using the ecosystem services concept to define a multi-criteria decision analysis. Ecological Economics 93:128-136. http://dx.doi.org/10.1016/j.ecolecon.2013.05.007

García-Llorente, M., I. Iniesta-Arandia, B. A. Willaarts, P. A. Harrison, P. Berry, M. del Mar Bayo, A. J. Castro, C. Montes, and B. Martín-López. 2015. Biophysical and sociocultural factors underlying spatial trade-offs of ecosystem services in semiarid watersheds. Ecology and Society 20(3):39. http://dx.doi. org/10.5751/ES-07785-200339

Garmendia, E., and G. Gamboa. 2012. Weighting social preferences in participatory multi-criteria evaluations: a case study on sustainable natural resource management. Ecological Economics 84:110-120. http://dx.doi.org/10.1016/j.ecolecon.2012.09.004

Hausmann, A., R. Slotow, J. K. Burns, and E. Di Minin. 2016. The ecosystem service of sense of place: benefits for human wellbeing and biodiversity conservation. Environmental Conservation 43(2):117-127. http://dx.doi.org/10.1017/S0376892915000314
Hayhoe, K., C. P. Wake, T. G. Huntington, L. Luo, M. D Schwartz, J. Sheffield, E. Wood, B. Anderson, J. Bradbury, A. DeGaetano, T. J. Troy, and D. Wolfe. 2007. Past and future changes in climate and hydrological indicators in the US Northeast. Climate Dynamics 28(4):381-407. http://dx.doi. org/10.1007/s00382-006-0187-8

Hostmann, M., M. Borsuk, P. Reichert, and B. Truffer. 2003. Stakeholder values in decision support for river rehabilitation. Large Rivers 15(1-4):491-505. http://dx.doi.org/10.1127/lr/15/2003/491

Howarth, R. B., and M. A. Wilson. 2006. A theoretical approach to deliberative valuation: aggregation by mutual consent. Land Economics 82(1):1-16. http://dx.doi.org/10.3368/le.82.1.1

Irvine, K. N., L. O’Brien, N. Ravenscroft, N. Cooper, M. Everard, I. Fazey, M. S. Reed, and J. O. Kenter. 2016. Ecosystem services and the idea of shared values. Ecosystem Services 21(B):184-193. http://dx.doi.org/10.1016/j.ecoser.2016.07.001

Iverson, L. R., A. M. Prasad, S. N. Matthews, and M. Peters. 2008. Estimating potential habitat for 134 eastern US tree species under six climate scenarios. Forest Ecology and Management 254 (3):390-406. https://doi.org/10.1016/j.foreco.2007.07.023

Karjalainen, T. P., M. Marttunen, S. Sarkki, and A.-M. Rytkönen. 2013. Integrating ecosystem services into environmental impact assessment: an analytic - deliberative approach. Environmental Impact Assessment Review 40:54-64. http://dx.doi.org/10.1016/j. eiar.2012.12.001

Keeney, R. L. 1992. Value-focused thinking: a path to creative decisionmaking. Harvard University Press, Cambridge, Massachusetts, USA.

Keeney, R. L., and H. Raiffa. 1976. Decisions with multiple objectives: preferences and value tradeoffs. Wiley, New York, New York, USA. http://dx.doi.org/10.1017/CBO9781139174084

Kenter, J. O. 2016. Integrating deliberative monetary valuation, systems modelling and participatory mapping to assess shared values of ecosystem services. Ecosystem Services 21(B):291-307. http://dx.doi.org/10.1016/j.ecoser.2016.06.010

Kenter, J. O., R. Bryce, M. Christie, N. Cooper, N. Hockley, K. N. Irvine, I. Fazey, L. O'Brien, J. Orchard-Webb, N. Ravenscroft, C. M. Raymond, M. S. Reed, P. Tett, and V. Watson. 2016a. Shared values and deliberative valuation: future directions. Ecosystem Services 21(B):358-371. https://doi.org/10.1016/j.ecoser.2016.10.006

Kenter, J. O., T. Hyde, M. Christie, and I. Fazey. 2011. The importance of deliberation in valuing ecosystem services in developing countries-evidence from the Solomon Islands. Global Environmental Change 21(2):505-521. http://dx.doi. org/10.1016/j.gloenvcha.2011.01.001

Kenter, J. O., M. S. Reed, and I. Fazey. 2016b. The deliberative value formation model. Ecosystem Services 21(B):194-207. https://doi.org/10.1016/j.ecoser.2016.09.015

Langhans, S. D., and J. Lienert. 2016. Four common simplifications of multi-criteria decision analysis do not hold for river rehabilitation. Plos One 11(3):e0150695. http://dx.doi. org/10.1371/journal.pone.0150695

Lo, A. Y., and C. L. Spash. 2013. Deliberative monetary valuation: in search of a democratic and value plural approach to 
environmental policy. Journal of Economic Surveys 27(4):768-789. http://dx.doi.org/10.1111/j.1467-6419.2011.00718.x

MacDonald, D. H., R. Bark, A. MacRae, T. Kalivas, A. Grandgirard, and S. Strathearn. 2013. An interview methodology for exploring the values that community leaders assign to multiple-use landscapes. Ecology and Society 18(1):29. http://dx. doi.org/10.5751/ES-05191-180129

Malinga, R., L. J. Gordon, R. Lindborg, and G. Jewitt. 2013. Using participatory scenario planning to identify ecosystem services in changing landscapes. Ecology and Society 18(4):10. http://dx.doi.org/10.5751/ES-05494-180410

Martin, D. M., and M. Mazzotta. 2018. Non-monetary valuation using multi-criteria decision analysis: sensitivity of additive aggregation methods to scaling and compensation assumptions. Ecosystem Services 29(A):13-22. http://dx.doi.org/10.1016/j. ecoser.2017.10.022

Masterson, V. A., R. C. Stedman, J. Enqvist, M. Tengö, M. Giusti, D. Wahl, and U. Svedin. 2017. The contribution of sense of place to social-ecological systems research: a review and research agenda. Ecology and Society 22(1):49. http://dx.doi.org/10.5751/ ES-08872-220149

Mavrommati, G., M. E. Borsuk, and R. B. Howarth. 2016. A novel deliberative multicriteria evaluation approach to ecosystem service valuation. Ecology and Society 22(2):39. http://dx.doi. org/10.5751/ES-09105-220239

Murphy, M. B., G. Mavrommati, V. R. Mallampalli, R. B. Howarth, and M. E. Borsuk. 2017. Comparing group deliberation to other forms of preference aggregation in valuing ecosystem services. Ecology and Society 22(4):17. http://dx.doi.org/10.5751/ ES-09519-220417

Neumayer, E. 2003. Weak versus strong sustainability: exploring the limits of two opposing paradigms. Second edition. Edward Elgar, Cheltenham, UK.

New Hampshire Department of Environmental Services (NHDES). 2016. Environmental fact sheet: the upper Merrimack River. WD-R\&L-13. NHDES, Concord, New Hampshire, USA. [online] URL: https://www.des.nh.gov/organization/commissioner/ pip/factsheets/rl/documents/rl-13.pdf

O’Neill, B. C., E. Kriegler, K. L. Ebi, E. Kemp-Benedict, K. Riahi, D. S. Rothman, B. J. van Ruijven, D. P. van Vuuren, J. Birkmann, K. Kok, M. Levy, and W. Solecki. 2017. The roads ahead: narratives for shared socioeconomic pathways describing world futures in the 21st century. Global Environmental Change 42:169-180. http://dx.doi.org/10.1016/j.gloenvcha.2015.01.004

Oikonomou, V., P. G. Dimitrakopoulos, and A. Y. Troumbis. 2011. Incorporating ecosystem function concept in environmental planning and decision making by means of multi-criteria evaluation: the case-study of Kalloni, Lesbos, Greece. Environmental Management 47(1):77-92. http://dx.doi.org/10.1007/ s00267-010-9575-2

Orchard-Webb, J., J. O. Kenter, R. Bryce, and A. Church. 2016. Deliberative democratic monetary valuation to implement the ecosystem approach. Ecosystem Services 21(B):308-318. http:// dx.doi.org/10.1016/j.ecoser.2016.09.005
Proctor, W., and M. Drechsler. 2006. Deliberative multicriteria evaluation. Environment and Planning C: Politics and Space 24 (2):169-190. http://dx.doi.org/10.1068/c22s

Randhir, T., and D. M. Shriver. 2009. Deliberative valuation without prices: a multiattribute prioritization for watershed ecosystem management. Ecological Economics 68(12):3042-3051. http://dx.doi.org/10.1016/j.ecolecon.2009.07.008

Ranger, S., J. O. Kenter, R. Bryce, G. Cumming, T. Dapling, E. Lawes, and P. B. Richardson. 2016. Forming shared values in conservation management: an interpretive-deliberative-democratic approach to including community voices. Ecosystem Services 21 (B):344-357. http://dx.doi.org/10.1016/j.ecoser.2016.09.016

Reichert, P., M. Borsuk, M. Hostmann, S. Schweizer, C. Spörri, K. Tockner, and B. Truffer. 2007. Concepts of decision support for river rehabilitation. Environmental Modelling and Software 22 (2):188-201. http://dx.doi.org/10.1016/j.envsoft.2005.07.017

Robbins, L. 1938. Interpersonal comparisons of utility: a comment. Economic Journal 48(192):635-641. http://dx.doi. org/10.2307/2225051

Rogers, S., J. Farrell, J. Loos, and C. Berg. 2014. New Hampshire's citizens value and use water in many ways: a preliminary report of the New Hampshire water and watershed survey-statewide perspectives with an oversample in the Piscataqua Region watershed. Plymouth State University, Plymouth, New Hampshire, USA. [online] URL: https://www.plymouth.edu/ center-for-the-environment/files/2013/01/Water-Survey-ReportMarch-2014.pdf

Samal, N. R., W. M. Wollheim, S. Zuidema, R. J. Stewart, Z. Zhou, M. M. Mineau, M. E. Borsuk, K. H. Gardner, S. Glidden, T. Huang, D. A. Lutz, G. Mavrommati, A. M. Thorn, C. P. Wake, and M. Huber. 2017. A coupled terrestrial and aquatic biogeophysical model of the upper Merrimack River watershed, New Hampshire, to inform ecosystem services evaluation and management under climate and land-cover change. Ecology and Society 22(4):18. http://dx.doi.org/10.5751/ES-09662-220418

Sandhu, H., B. Clarke, R. Baring, S. Anderson, C. Fisk, S. Dittmann, S. Walker, P. Sutton, I. Kubiszewski, and R. Costanza. 2018. Scenario planning including ecosystem services for a coastal region in South Australia. Ecosystem Services 31(A):194-207. http://dx.doi.org/10.1016/i.ecoser.2018.04.006

Spash, C. L. 2007. Deliberative monetary valuation (DMV): issues in combining economic and political processes to value environmental change. Ecological Economics 63(4):690-699. http://dx.doi.org/10.1016/j.ecolecon.2007.02.014

Straton, A. T., S. Jackson, O. Marinoni, W. Proctor, and E. Woodward. 2011. Exploring and evaluating scenarios for a river catchment in northern Australia using scenario development, multi-criteria analysis and a deliberative process as a tool for water planning. Water Resources Management 25(1):141-164. http://dx. doi.org/10.1007/s11269-010-9691-Z

Thorn, A. M., C. P. Wake, C. D. Grimm, C. R. Mitchell, M. M. Mineau, and S. V. Ollinger. 2017. Development of scenarios for land cover, population density, impervious cover, and conservation in New Hampshire, 2010-2100. Ecology and Society 22(4):19. https://doi.org/10.5751/ES-09733-220419 
Uhde, B., W. A. Hahn, V. C. Griess, and T. Knoke. 2015. Hybrid MCDA methods to integrate multiple ecosystem services in forest management planning: a critical review. Environmental Management 56(2):373-388. http://dx.doi.org/10.1007/s00267-015-0503-3

Von Winterfeldt, D., and W. Edwards. 1986. Decision analysis and behavioral research. Cambridge University Press Cambridge, UK.

Wake, C. P., E. A. Burakowski, P. Wilkinson, K. Hayhoe, A. Stoner, C. Keeley, and J. LaBranche. 2014. Climate change in southern New Hampshire: past, present and future. Report. Sustainability Institute, University of New Hampshire, Durham, New Hampshire, USA. [online] URL: https://scholars.unh.edu/ sustainability/2

Wardropper, C. B., S. Gillon, A. S. Mase, E. A. McKinney, S. R. Carpenter, and A. R. Rissman. 2016. Local perspectives and global archetypes in scenario development. Ecology and Society 21(2):12. http://dx.doi.org/10.5751/ES-08384-210212

Wilson, M. A., and R. B. Howarth. 2002. Discourse-based valuation of ecosystem services: establishing fair outcomes through group deliberation. Ecological Economics 41(3):431-443. http://dx.doi.org/10.1016/S0921-8009(02)00092-7

Wollheim, W. M., B. J. Peterson, S. M. Thomas, C. H. Hopkinson, and C. J. Vörösmarty. 2008. Dynamics of N removal over annual time periods in a suburban river network. Journal of Geophysical Research: Biogeosciences 113(G3):03038. http://dx.doi.

org/10.1029/2007JG000660 